\title{
ATHEROSCLEROTIC PLAQUE REGRESSION: CAUSE OF BYPASS GRAFT OCLUSSION
}

\section{Cojocaru Lucia, ${ }^{1,2}$, Avram Anamaria ${ }^{3}$, Chioncel Valentin³, Rusali Andreī', Parepa Irinel 1,2}

${ }^{1}$ Faculty of Medicine, University "Ovidius" of Constanța

${ }^{2}$ Emergency Clinical COunty Hospital of Constanța, Cardiology Clinic

${ }^{3}$ Emergency Clinical Hospital "Bagdasar-Arseni”, Bucharest

\section{ABSTRACT}

We present a case of a patient who had coronary artery bypass grafting during surgery for severe aortic stenosis. Seven months after surgery the arterial graft was occluded following native coronary artery disease regression. The heart team must consider this possibility when assessing the requirement for bypass grafts in a borderline lesion.

Keywords: bypass graft, atherosclerotic plaque regression, atherosclerosis

\section{Introduction}

Atherosclerosis is a systemic disease characterized by narrowing of blood vessels due to the formation of atheromatous plaque or atheroma(1). Atheroma is the deposition of fatty material and cholesterol within the inner wall of arteries that makes arterial lumen stenotic (1).

Generally, atherosclerosis was viewed as a progressive, nonremitting disease. Although the concept of plaque regression was earlier refuted, recent case reports (2-4) and studies (5-10) have showed atherosclerosis regression to be a realistic goal in some patients (1). Plaque regression, as viewed today, delves over the prospect of treating vulnerable plaques beyond just stabilization (1). It emphasizes on aggressive and/or long-term therapy (especially lipid modifying therapies statins) for the reduction in plaque volume and the reversal of the arterial endothelium to its normal functional state (1). Not only lifestyle changes and aggressive lipid-lowering therapy can retard the progression of atherosclerotic lesions and promote the disease regression. Changes in the anatomy and hemodinamics after coronary artery bypass grafting $(\mathrm{CABG})$ can significantly affect the evolution of coronary atherosclerosis (11).

We present a case of coronary artery bypass occlusion following native coronary artery disease regression in a patient who had CABG 
during surgery for severe aortic stenosis.

\section{Clinical Case}

A 77-years old woman, with hypertension, dyslipidemia, diabetes mellitus, rheumatoid arthritis and hypothyroidism, with bioprosthetic aortic valve (Medtronic 21) replacement in November 2015 for symptomatic severe aortic stenosis and CABG with the left internal mammary artery (LIMA) to the left anterior descending artery (LAD) for $70 \%$ stenosis of LADII during the time of aortic surgery presents for moderate effort angina. A computerized tomography coronary angiography performed in June 2016 revealed total occlusion of the bypass graft from its origin from left subclavicular artery till its attachment in the middle third of the LAD.

The clinical exam revealed an overweight patient with a blood pressure of $130 / 80 \mathrm{mmHg}$, heart rate of $55 \mathrm{bpm}$, without signs of pulmonary or systemic stasis.

Electrocardiogram (ECG) on admission: sinus rhythm, 60bpm, QRS axis $=0$ degree, negative $\mathrm{T}$ waves in V1-V3 (similar to the previous ECGs) and isolated premature atrial beat (Figure 1).

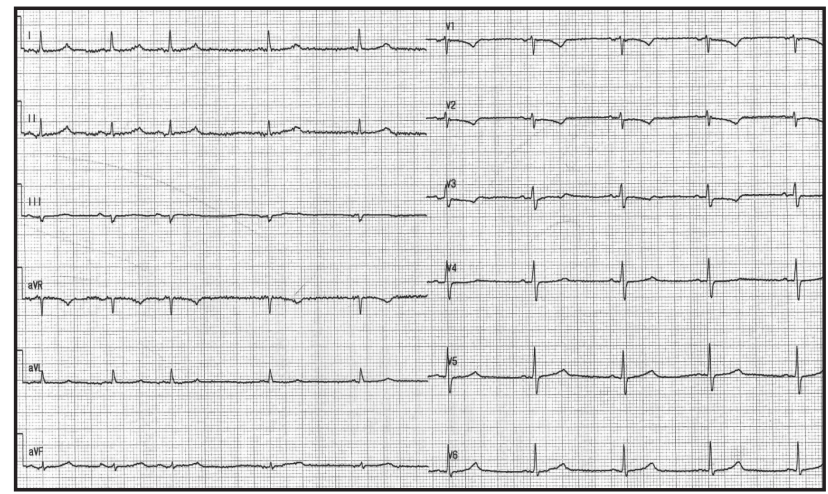

Figure 1: Electrocardiogram on admission (description in text)

Laboratory tests revealed a mild normochromic, normocytic anemia, transitory azotate retention, hyperglycemia, normal myocardial necrosis markers and a lipid profile with normal total cholesterol $(152 \mathrm{mg} / \mathrm{dl})$, LDLcholesterol $(68.2 \mathrm{mg} / \mathrm{dl})$ and HDL-cholesterol $(50 \mathrm{mg} / \mathrm{dl})$ with mild hypertriglyceridemia $(169 \mathrm{mg} / \mathrm{dl})$.

On echocardiography there was mild left ventricular hypertrophy, preserved left ventricular ejection fraction (55\%), type I diastolic dysfunction, mitral regurgitation second degree and normal aortic prosthetic valve function (Figure 2).

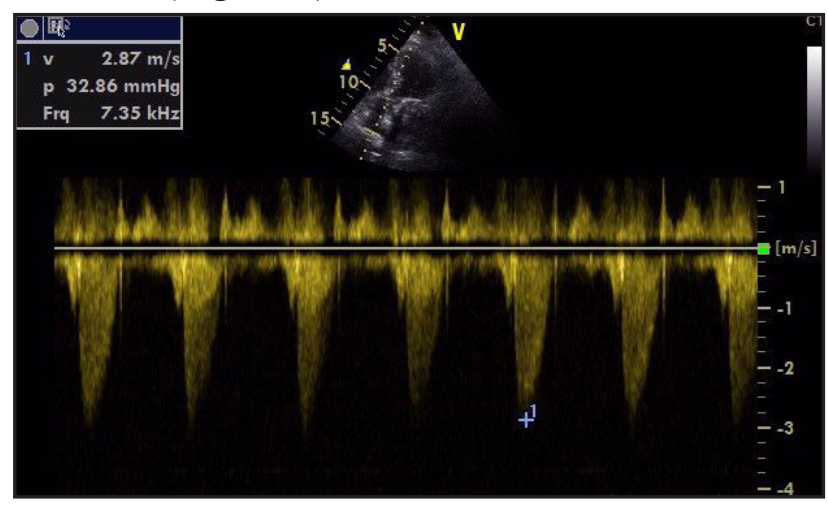

Figure 2: Echocardiography-Continuous wave Doppler showing normal peak gradient across the aortic prosthetic valve

The coronarography confirmed the occlusion of the arterial bypass graft (Figure 3 ) and revealed a $50 \%$ stenosis of LAD at the emergence of $2^{\text {nd }}$ diagonal branch (Figure 4) (as opposed to the $70 \%$ stenosis at the same level on the pre-surgery evaluation) (Figure 5) and a 50$60 \%$ stenosis of the intermediary branch.

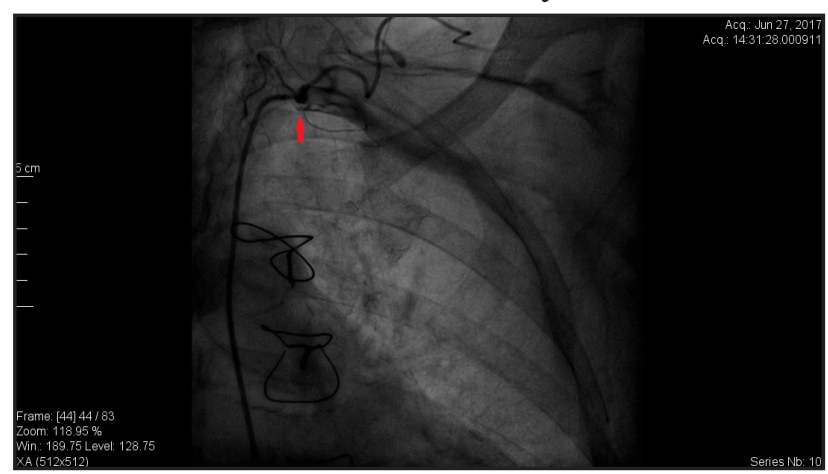

Figure 3: Coronarography from June 2017 showing occlusion of the arterial bypass graft from its origin (red arrow)

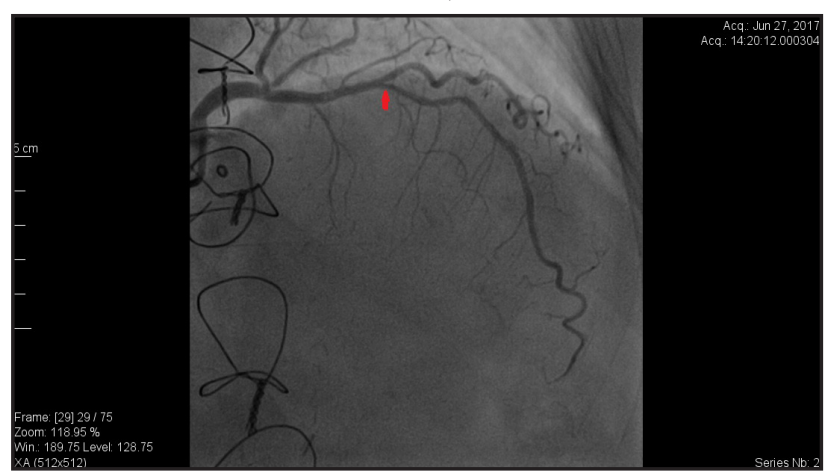

Figure 4: Coronarography from June 2017 showing image from 2015 showing $50 \%$ stenosis of LAD at the emergence of $2^{\text {nd }}$ diagonal branch (red arrow) 


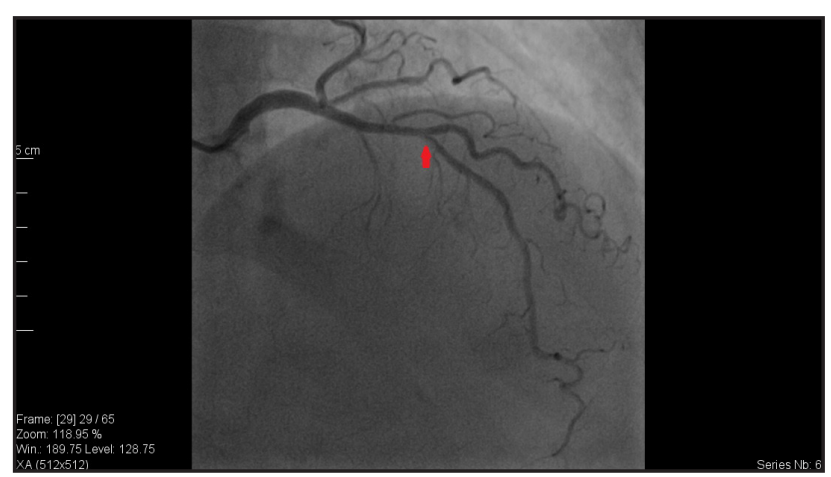

Figure 5: Coronarography from June 2015 showing 70\% stenosis of LAD at the emergence of $2^{\text {nd }}$ diagonal branch (red arrow)

Given the stable character of the angina and the insignificant coronary stenosis the heart team decided in favor of the conservative approach with optimized medical treatment (antiplatelet therapy, beta-blocker, ivabradine, long lasting nitrate, sartan and statin).

\section{Discussion}

Aortic valve stenosis is the most common valvular heart disease in the elderly population and frequently occurs in conjunction with coronary artery disease (CAD) (12-14). More than $50 \%$ of patients with aortic stenosis over 70 years of age also have CAD (15)[15]. This strong association is thought to be due to common physiopathology and shares similar risk factors (age, smoking, hypertension and hyperlipidemia) $(16,17)$.

Although there has never been a randomized controlled trial of surgical aortic valve replacement (SAVR) with or without CABG of concomitant CAD at the time of the surgery [16], the combined approach is the one recommended by the current practice guidelines. The American College of Cardiology, the American Heart Association, the European Society of Cardiology and the European Association for CardioThoracic Surgery guidelines on valvular heart disease advocate (Class I recommendation) that patients undergoing aortic valve replacement who have significant $\mathrm{CAD}(\geq 70 \%$ reduction in luminal diameter in major coronary arteries) should be treated by bypass grafting $(18,19)$. This recommendation is based more on opinion than evidence. In patients undergoing aortic valve replacement that also have significant CAD, the combination of CABG and SAVR reduces the rates of perioperative myocardial infarction, perioperative mortality, late mortality, and morbidity when compared with patients not undergoing simultaneous $\mathrm{CABG}$, even though the combined operation carries a small but real increased risk of mortality (18). The survival benefit was seen mostly in those that received a LIMA to the $\operatorname{LAD}(16,20)$ as was the case with our patient.

Patency rates for arterial grafts are very good (at 10 years are as high as 95 percent) (21). The cases in which the arterial graft develops a stenosis or becomes occluded early after the surgery are related to operative issues (ie, technical harvest problems, distal anastomotic technique, perioperative management, including the variable use and timing of antiplatelet therapy, vasospasm, and statin therapy) and patient-related anatomical issues (proximal stenosis, presence of competitive flow in the bypassed vessel, size of distal vessel, as well as plaquing and diffuse disease in the bypassed vessel) (22).

In our patient the most probable cause for graft failure was the competitive flow in the native bypassed vessel due to the regression of the atherosclerotic stenosis. The question that arises is what was responsible for this regression? It is known that aggressive cholesterol lowering with statins slows progression of atherosclerosis, reduces new lesions' formation or even causes atheroma regression and the beneficial effects of increased HDL-cholesterol are also recognized (3, 23-25). A LDL-cholesterol/HDL-cholesterol ratio under 1.5 was associated with the regression of plague $(24,26)$ which was the case with our patient where this ratio was 1.3. The bypass grafting can also have an influence on native coronary artery disease regression. Data derived from the RAPCO trial (Radial Artery Patency and Clinical Outcomes) showed that $45 \%$ of the patients who had CABG surgery demonstrated regression in 1 or more native coronary vessels (11). These data shown that native coronary lesions were more likely to exhibit regression in females and diabetic patients, if the revascularized coronary vessels where in the left circulation and in those with pre-existing severe stenosis (more than $70 \%$ ) (11). Arterial grafts appear to protect 
the native circulation against disease progression and might also induce regression due to them being metabolically active (their endothelium is able to release vasoactive substances and endothelial progenitor cells) $(11,27)$. The regression of the disease in the native vessel will, in turn, affect arterial graft patency by increasing the coronary flow competition to the graft and will double the risk of graft failure (11).

Taking into account these data particular attention must be paid to the evaluation of the degree and significance of a coronary stenosis prior to $\mathrm{CABG}$, which in patients with severe aortic stenosis is very challenging. Angina is present in a patient with severe aortic stenosis even in the absence of significant CAD so it can't be used to determine the significance of a stenosis, and an ECG stress test is contraindicated in these patients. Given inter- and intraobserver variability with visual assessment of the coronarographyc stenosis, we need a more objective method. Quantitative Coronary Analysis can be used but it can be inaccurate in extremely tortuous and calcified vessels which are common in patients with severe aortic stenosis, and in this circumstance intracoronary imaging might more useful $(16,28)$. The fractional flow reserve is not validated in severe aortic stenosis (16) and the instantaneous wave-free ratio is under investigation (29).

\section{Conclusions}

Regression of native coronary artery disease can be observed in close to one half of patients after CABG and can be a cause for graft failure. The heart team must take this into account when assessing the indication of CABG, especially in a borderline lesion, when they will have to use an objective method to determine the degree and significance of the stenosis.

\section{References}

1. Dave T, Ezhilan J, Vasnawala H, Somani V. Plaque regression and plaque stabilisation in cardiovascular diseases. Indian J Endocrinol Metab. 2013;17(6):983-9.
2. Chockalingam P, Vinayagam NS, Chockalingam V, Chockalingam A. Remarkable regression of coronary atherosclerosis: An interplay of pharmacotherapeutic and lifestyle factors. Indian Heart J. 2016;68(2):188-9.

3. De Rosa S, Mongiardo A, Spaccarotella C, Torella D, Caiazzo G. Spontaneous Regression of Subocclusive Coronary Stenosis: Does Time Heals All Wounds. J Clin Exp Cardiolog. 2014;5(294):2 .

4. Shiga Y, Miura S-i, Nishikawa H, Nakamura A, Arimura T, Mitsutake R, et al. Regression of coronary plaque after coronary artery bypass graft. Journal of Cardiology Cases. 2012;5(2):e92-e5.

5. Jensen LO, Thayssen P, Pedersen KE, Stender S, Haghfelt T. Regression of coronary atherosclerosis by simvastatin: a serial intravascular ultrasound study. Circulation. 2004;110(3):265-70.

6. Nissen SE. Halting the progression of atherosclerosis with intensive lipid lowering: results from the Reversal of Atherosclerosis with Aggressive Lipid Lowering (REVERSAL) trial. Am J Med. 2005;118 Suppl 12A:22-7.

7. Nissen SE, Tuzcu EM, Schoenhagen P, Brown BG, Ganz P, Vogel RA, et al. Effect of intensive compared with moderate lipidlowering therapy on progression of coronary atherosclerosis: a randomized controlled trial. JAMA. 2004;291(9):1071-80.

8. Nissen SE, Nicholls SJ, Sipahi I, Libby P, Raichlen JS, Ballantyne CM, et al. Effect of very high-intensity statin therapy on regression of coronary atherosclerosis: the ASTEROID trial. Jama. 2006;295(13):155665.

9. Okazaki S, Yokoyama T, Miyauchi K, Shimada K, Kurata T, Sato H, et al. Early statin treatment in patients with acute coronary syndrome: demonstration of the beneficial effect on atherosclerotic lesions by serial volumetric intravascular ultrasound analysis during half a year after coronary event: the ESTABLISH Study. Circulation. 2004;110(9):1061-8.

10. Watts GF, Lewis B, Brunt JN, Lewis ES, Coltart DJ, Smith LD, et al. Effects on 
coronary artery disease of lipid-lowering diet, or diet plus cholestyramine, in the St Thomas' Atherosclerosis Regression Study (STARS). Lancet. 1992;339(8793):563-9.

11. Zhu YY, Nguyen TT, Buxton BF, Hare DL, Hayward PA. Regression of coronary disease after bypass surgery: Urban myth or common finding? J Thorac Cardiovasc Surg. 2014;148(1):53-9.

12. Paradis J-M, Fried J, Nazif T, Kirtane A, Harjai K, Khalique $\mathrm{O}$, et al. Aortic stenosis and coronary artery disease: what do we know? What don't we know? A comprehensive review of the literature with proposed treatment algorithms. European heart journal. 2014;35(31):2069-82.

13. Rapp AH, Hillis LD, Lange RA, Cigarroa JE. Prevalence of coronary artery disease in patients with aortic stenosis with and without angina pectoris. The American journal of cardiology. 2001;87(10):1216-7.

14. Vandeplas A, Willems JL, Piessens J, De Geest H. Frequency of angina pectoris and coronary artery disease in severe isolated valvular aortic stenosis. Am J Cardiol. 1988;62(1):117-20.

15. Iung B. Interface between valve disease and ischaemic heart disease. Heart. 2000;84(3):347-52.

16. El Sabbagh A, Nishimura RA. Clinical conundrum of coronary artery disease and aortic valve stenosis. Am Heart Assoc; 2017.

17. Stewart BF, Siscovick D, Lind BK, Gardin JM, Gottdiener JS, Smith VE, et al. Clinical factors associated with calcific aortic valve disease. Cardiovascular Health Study. J Am Coll Cardiol. 1997;29(3):630-4.

18. Nishimura RA, Otto CM, Bonow RO, Carabello BA, Erwin JP, 3rd, Guyton RA, et al. 2014 AHA/ACC Guideline for the Management of Patients With Valvular Heart Disease: a report of the American College of Cardiology/American Heart Association Task Force on Practice Guidelines. Circulation. 2014;129(23):e521-643.

19. Baumgartner H, Falk V, Bax JJ, De Bonis M, Hamm C, Holm PJ, et al. 2017 ESC/EACTS Guidelines for the management of valvular heart disease. Eur Heart J. 2017;38(36):273991.
20. Thalji NM, Suri RM, Daly RC, Greason KL, Dearani JA, Stulak JM, et al. The prognostic impact of concomitant coronary artery bypass grafting during aortic valve surgery: implications for revascularization in the transcatheter era. J Thorac Cardiovasc Surg. 2015;149(2):451-60.

21. Tatoulis J, Buxton BF, Fuller JA. Patencies of 2127 arterial to coronary conduits over 15 years. Ann Thorac Surg. 2004;77(1):93-101.

22. Aranki S, Aroesty J. Coronary artery bypass graft surgery: Causes and rates of graft failure 2018 [updated 2017. Available from: https://www.uptodate.com.

23. Vos J, De Feyter P, Kingma J, Emanuelsson $\mathrm{H}$, Legrand V, Winkelmann B, et al. Evolution of coronary atherosclerosis in patients with mild coronary artery disease studied by serial quantitative coronary angiography at 2 and 4 years follow-up. European heart journal. 1997;18(7):1081-9.

24. Nicholls SJ, Tuzcu EM, Sipahi I, Grasso AW, Schoenhagen P, Hu T, et al. Statins, high-density lipoprotein cholesterol, and regression of coronary atherosclerosis. Jama. 2007;297(5):499-508.

25. Toth PP. High-Density Lipoprotein and Cardiovascular Risk. Circulation. 2004;109(15):1809-12.

26. Fukuda Y, Miura S-i, Tsuchiya Y, InoueSumi Y, Kubota K, Takamiya Y, et al. Lower frequency of non-target lesion intervention in post-successful percutaneous coronary intervention patients with an LDL to HDL cholesterol ratio below 1.5. International journal of cardiology. 2011;149(1):120-2.

27. Dimitrova KR, Hoffman DM, Geller CM, Dincheva G, Ko W, Tranbaugh RF. Arterial grafts protect the native coronary vessels from atherosclerotic disease progression. Ann Thorac Surg. 2012;94(2):475-81.

28. Tu S, Xu L, Ligthart J, Xu B, Witberg K, Sun $\mathrm{Z}$, et al. In vivo comparison of arterial lumen dimensions assessed by co-registered threedimensional (3D) quantitative coronary angiography, intravascular ultrasound and optical coherence tomography. Int $\mathrm{J}$ Cardiovasc Imaging. 2012;28(6):1315-27.

29. Sen S, Escaned J, Malik IS, Mikhail GW, Foale RA, Mila R, et al. Development 
and validation of a new adenosineindependent index of stenosis severity from coronary wave-intensity analysis: results of the ADVISE (ADenosine Vasodilator Independent Stenosis Evaluation) study. J Am Coll Cardiol. 2012;59(15):1392-402. 